\title{
Risk factors for recurrent wheezing after bronchiolitis in infants: 2-year follow up in China
}

\section{Sainan Chen}

Children's Hospital of Soochow university

\section{Wenjing Gu}

children's hospital of soochow university

\section{Min Wu}

children's hospital of soochow university

Chuangli Hao

children's hospital of soochow university

Canhong Zhu

children's hospital of soochow university

\section{Xuejun Shao}

children's hospital of soochow university

Yuqing Wang ( $\square$ wang_yu_qing@126.com )

\section{Research article}

Keywords: bronchiolitis, recurrent wheezing, eczema

Posted Date: May 6th, 2020

DOI: https://doi.org/10.21203/rs.3.rs-26354/v1

License: (c) (1) This work is licensed under a Creative Commons Attribution 4.0 International License. Read Full License

Version of Record: A version of this preprint was published on March 10th, 2021. See the published version at https://doi.org/10.1186/s12879-021-05937-8. 


\section{Abstract}

Objective: To investigate the incidence of post-bronchiolitis recurrent wheezing and the risk factors.

Methods: Infants with bronchiolitis were enrolled from November 2016 through March 2017. 24 healthy children were enrolled as the control group. Nasopharyngeal aspirates were obtained for detecting respiratory virus including by using RT-PCR and direct immunofluorescent assay. The serum levels of cytokine including TSLP, IL2, IL13, TIMP-1, MMP-9, IL33, IL5, IL4, IL25, TNF- $a$ and MIP-1a were measured by using flow cytometry. The patients were followed every 3 months for a duration of 2 years by telephone or outpatient.

Results: 1.89 infants were enrolled, of which 81 patients were successfully followed up. 2. $22.2 \%$ of the patients experienced recurrent wheezing episodes. 3 . The proportion of eczema, systemic glucocorticoid treatment and patients with moderate to severe condition were significantly higher in recurrent wheezing group than in non-recurrent wheezing group $(52.4 \%$ vs $83.3 \% ; 36.5 \%$ vs $66.7 \% ; 33.3 \%$ vs $61.1 \%$, respectively, both $\mathrm{P}<0.05)$; The serum level of TNF- a was lower in recurrent wheezing group $(P<0.05)$ ;The serum levels of IL-4IIL-5IIL-25IL-33 were significantly higher among patients without recurrent wheezing $(P<0.05)$. 4. Logistic regression analysis showed that eczema was an independent risk factor for post-bronchiolitis recurrent wheezing ( $\mathrm{OR}=7.488 ; 95 \% \mathrm{Cl}, 1.447-38.759 ; \mathrm{P}=0.016)$. Conclusion: The prevalence of recurrent wheezing among infants after bronchiolitis was $22.2 \%$ in 2-year follow-up. Eczema is the only independent risk factor and no correlation was found between the specific virus and disease severity with post-bronchiolitis recurrent wheezing.

This work was supported by the National Natural Science Foundation of China, No.81573167; Jiangsu Science and Technology Department, No. BE2017657; Science and Technology Project of Suzhou, No. SYSD2017092; No. LCZX201809

\section{Introduction}

Acute bronchiolitis is a common lower respiratory tract disease characterized by inflammation of the bronchioles with a diameter of 75-300um. It is often caused by viral infection in infants under two years with the symptoms of wheezing, cough, tachypnea and chest retractions. Respiratory syncytial virus (RSV) is the most common cause of acute bronchiolitis among infants ${ }^{[1,2]}$.

Recurrent wheezing can be seen after acute bronchiolitis attack ${ }^{[3]}$. Follow up data from abroad showed that the incidence of post-bronchiolitis recurrent wheezing could be $31 \%[4]$ and about $48 \%$ of patients were diagnosed with asthma at the age of 7 years old after severe RSV bronchiolitis ${ }^{[5]}$. In a follow-up study in China ${ }^{[6]}, 35.1 \%(26 / 74)$ of the infants at 6 months or less with bronchiolitis had recurrent wheezing by the age of 3 years. However, the mechanism of recurrent wheezing after bronchiolitis has not been elucidated, and the risk factors are still controversial. 
Current research suggests that risk factors for post-bronchiolitis recurrent wheezing are as follows:

allergy $^{[7]}$, the elevation of specific IgE level ${ }^{[8]}$, family history of asthma ${ }^{[9]}$, passive smoking ${ }^{[10]}$, disease severity ${ }^{[11]}$ and so on. A large number of epidemiological and prospective studies showed that respiratory syncytial virus infection is a risk factor for recurrent wheezing or asthma after bronchiolitis ${ }^{[5,12,13]}$. In recent years, more and more attention has been paid to the relationship between cytokine level and postbronchiolitis recurrent wheezing. One study has shown that IL-3 can be used as a predictor of recurrent wheezing after bronchiolitis ${ }^{[14]}$, and some scholar believes that MIP-1 $a$ can be used as a biomarker to predict recurrent wheezing ${ }^{[15]}$. However, no biomarkers for the prediction of recurrent wheezing are available for infants experiencing bronchiolitis.

It is of great significance for treatment and prevention to understand the risk factors of recurrent wheezing post bronchiolitis. However, there are few follow-up studies on bronchiolitis in China, and the risk factors of recurrent wheezing are still unclear so far. The objective of this study was, therefore, to identify potential predicting factors for the recurrent wheezing in infants post bronchiolitis through a twoyear follow-up study.

\section{Methods}

\section{Patients}

Patients diagnosed with bronchiolitis and hospitalized into the Department of Respiratory Disease at Children's Hospital Soochow University, China, from November 2016 through March 2017, were enrolled in this study. Recurrent wheezing was defined as two or more episodes following the initial bronchiolitis. We also enrolled 24 healthy infants (median age 3.5 months, range 3-24 months, 15 (15.1\%) males) as the control. The study was approved by the ethics committees of Children's Hospital Soochow University (Approval No.:2016050). Informed consent was obtained from the parents for all children enrolled in this study.

Inclusion criteria: 1). Age was1-24 months. 2). Patients were hospitalized with bronchiolitis. 3). Bronchiolitis was defined as the first wheezing episode with the symptoms of cough, tachypnea and chest retractions.

Exclusion criteria: Neuromuscular disease, congenital airway deformity, congenital heart disease, gastroesophageal reflux disease, bronchial foreign body inhalation and primary or secondary immune deficiency or other immune-associated diseases were excluded.

\section{Sample collection}

Nasopharyngeal aspirates were obtained using a suction catheter to passed through the nose into the lower part of the pharynx. Blood specimens were also collected. 


\section{Detection of seven common viruses by direct immunofluorescent assay (DFA)}

DFA was used to detect syncytial virus infection (RSV), influenza virus A (IVA), influenza virus B (IVB), parainfluenza virus (PIV) I, PIV II, PIV III, and adenovirus (ADV). All assay kits were purchased from Chemicon (USA) and all staining procedures were performed according to the manufacturer's instructions. Immunostained preparations were viewed with a fluorescence microscope (Leica 020518.500, Germany).

\section{Detection of the hMPV, hRV, hBoV gene by real-time polymerase chain reaction (RT-PCR)}

For hMPV detection, primers were designed to specifically amplify the $\mathrm{N}$ gene (213 bps). The forward and reverse primers were hMPV-F:5'- AACCGTGTACTAAGTGA

TGCACTC-3' and hMPV-R:5'- CATTGTTTGACCGGCCCCATAA-3', respectively. The cyclic temperature settings were $94{ }^{\circ} \mathrm{C}, 30 \mathrm{~s} ; 55^{\circ} \mathrm{C}, 30 \mathrm{~s} ; 68^{\circ} \mathrm{C}, 30 \mathrm{~s}$; amplified by

45 cycles with the last at $68^{\circ} \mathrm{C}$ for $7 \mathrm{~min}$.

For hRV detection, the primers and probe sequences were HRV-F: 5'-TGGACAGGGTGTGAAGAGC-3';HRVR:5'-CAAAGTAGTCGGTCCCATCC-3';HRV-probe:FAM-TCCTCCGGCCCCTGA ATG-TAMRA. The cyclic temperature settings were $94^{\circ} \mathrm{C}, 30 \mathrm{~s} ; 56^{\circ} \mathrm{C}, 30 \mathrm{~s} ; 72^{\circ} \mathrm{C}, 30 \mathrm{~s}$; amplified, 40 cycles.

For hBoV detection, the primers and probe sequences were HBoV-F:5'-TGACATTCAACTACCAACAACCTG3';HBoV-R:5'CAGATCCTTTTCCTCCTCC

AATAC-3'; HBoV-probe: FAMAGCACCACAAAACACCTCAGGGG-TAMRA. The cyclic temperature settings were $94^{\circ} \mathrm{C}, 30 \mathrm{~s} ; 56^{\circ} \mathrm{C}, 30 \mathrm{~s} ; 72^{\circ} \mathrm{C}, 30 \mathrm{~s}$; amplified by 40 cycles.

\section{Detection of Peripheral blood}

The following blood tests were done in all of the patients: blood cell count, serum total lgE, antigenspecific lgE, humoral and cellular immunity.

\section{Detection of serum levels of cytokine}

The peripheral blood was centrifuged at $2500 \mathrm{r} / \mathrm{min}$ for 5 minutes. Supernatants were frozen at $-80^{\circ} \mathrm{C}$. Serum levels of cytokine (TNF-a, IL-2, IL-13, IL-4, IL-5, IL-25, IL-33, TSLP, TIMP-1, MMP-9 and MIP-1a) were measured by using flow cytometry. Flow cytometry (Beckman Coulter, Brea, CA, USA) was performed according to the manufacturer's instructions (Immunotech, Marseille, France). All assay kits were purchased from BEIJING TONGSHENG SHIDAI BIOTECH CO., LTD. Data were automatically processed and analyzed by using FCAP Array 3.0 with the standard curve produced from the cytokine standard. 
Each patient's data, including age, gender, gestational age at delivery, birth weight, feeding patterns, eczema, family history of asthma, exposure to smoking, pet contact were recorded.

\section{Parent/guardian interviews}

These patients were followed up every 3 months for 2-year period after being discharged by outpatient or telephone.

\section{Statistical analysis}

SPSS version 18.0 software was used for data analysis. Distribution normality of continuous data was tested by P-P plots methods before the comparison. Data with normal distribution was represented as mean $\pm S D$ and analyzed by $t$ test. Continuous data with non-normal distribution was represented as median(minimum-maximum) and analyzed with the Mann-Whitney $U$ test. Categorical data were represented as frequency and analyzed with Chi square examination. Predictors of recurrent wheezing were tested by using a stepwise logistic regression model.

\section{Results}

\section{Recruitment and general characteristics}

89 infants (male 56 and female 33, mean age of 3 months) and 24 controls (male 15 and female 9, mean age 3.5 months) were enrolled. There was no significant difference in age and gender between the two groups $(p>0.05)$.

\section{Viral detection rate in clinical specimens}

Positive rates of respiratory viruses were $50.6 \%$. The most common pathogen was RSV (44.4\%), followed by HRV (3.7\%), HBoV (2.5\%) and 2.5\% were co-infected with RSV and HRV. 
Table 1

Virus distribution in the 81 infants with and without recurrent wheezing

\begin{tabular}{|c|c|c|c|}
\hline \multirow[t]{2}{*}{ Viruses } & \multirow[t]{2}{*}{ Total, $\mathrm{n}=81$, no. (\%) } & \multicolumn{2}{|l|}{ RT-PCR } \\
\hline & & $R W(-), n=63$, no. $(\%)$ & $R W(+), n=18$, no. $(\%)$ \\
\hline RSV & $36(44.4)$ & $29(47.6)$ & $7(44.4)$ \\
\hline HRV & $3(3.7)$ & $2(3.2)$ & $1(5.6)$ \\
\hline Metapneumovirus & $0(0)$ & $0(0)$ & $0(0)$ \\
\hline HBoV & $2(2.5)$ & $1(1.6)$ & $1(5.6)$ \\
\hline Parainfluenza virus & $0(0)$ & $0(0)$ & $0(0)$ \\
\hline Influenza virus & $0(0)$ & $0(0)$ & $0(0)$ \\
\hline Adenovirus & $0(0)$ & $0(0)$ & $0(0)$ \\
\hline One virus & $75(92.6)$ & $60(95.2)$ & 15(83.3) \\
\hline Two viruses & $2(2.5)$ & $1(1.6)$ & $1(5.6)$ \\
\hline Not detected & $4(4.9)$ & $2(3.2)$ & $2(11.1)$ \\
\hline
\end{tabular}

\section{Follow-up results}

A total of 81 patients were successfully followed up and 8 patients were lost due to wrong telephone number. Of the 81 infants whose parents answered the telephone interview at every three months, 22 (27.2\%) infants experienced one single episode and 18 (22.2\%) infants experienced recurrent wheezing including $3(3.7 \%)$ having 2 episodes, 18.5\% $(n=15)$ having $\geq 3$ episodes. (Fig. 1).

\section{Baseline data between patients with and without recurrent wheezing episodes}

Eczema was more common in patients with recurrent wheezing episodes $(P=0.037$, Continuity correction). There were no significant differences between patients with and without recurrent wheezing episodes in sex, age, premature birth, feeding patterns, family history of asthma and so on $(P>0.05)$ (Table 2). 
Table 2

Comparison of baseline data between patients with and without recurrent wheezing episodes

\begin{tabular}{|c|c|c|c|}
\hline Factors & $R W(-), n=63$ & $R W(+), n=18$ & $P$ \\
\hline Sex(male) & 65.1 & 50.0 & 0.280 \\
\hline Age(months) & $5.20(1.03-19)$ & $3.97(1.30-9.83)$ & 0.481 \\
\hline premature birth & 4.8 & 0 & $\triangle 1.000$ \\
\hline LBW & 6.3 & 0 & $\triangle_{0.570}$ \\
\hline Macrosomia & 6.3 & 11.1 & $\triangle_{0.610}$ \\
\hline \multicolumn{4}{|l|}{ Feeding patterns } \\
\hline breast feeding & 55.6 & 61.1 & 0.675 \\
\hline Artificial feeding & 11.1 & 16.7 & *0.821 \\
\hline mixed feeding & 33.3 & 22.2 & *0.541 \\
\hline eczema & 52.4 & 83.3 & $\star 0.037$ \\
\hline Family history of asthma & 6.3 & 11.1 & $\triangle_{0.610}$ \\
\hline Exposure to smoking & 46.0 & 50.0 & 0.795 \\
\hline Pet contact & 1.6 & 5.6 & $\triangle_{0} .397$ \\
\hline \multicolumn{4}{|c|}{$\begin{array}{l}\text { note: RW(+), patients with recurrent wheezing episodes; RW }(-) \text {, patients without recurrent wheezing } \\
\text { episodes; LBW, low birth weight. }\end{array}$} \\
\hline \multicolumn{4}{|c|}{$\begin{array}{l}\text { Data are expressed as } \% \text { of positive cases, mean } \pm \text { SD or median (minimum-maximum), unless } \\
\text { otherwise stated. } \\
\text { * Continuity correction. }\end{array}$} \\
\hline$\triangle$ Fisher exact test. & & & \\
\hline
\end{tabular}

\section{Clinical characteristics between patients with and without recurrent wheezing episodes}

There were no significant differences between patients with and without recurrent wheezing episodes in fever, feeding difficulty, chest retractions and so other clinical characteristics $(P>0.05)$, however, The proportion of patients with moderate to severe condition in recurrent wheezing groups was higher than that of patients without recurrent wheezing groups $(P=0.033)$ (Table 3$)$. 
Table 3

Comparison of clinical characteristics between patients with and without recurrent wheezing episodes

\begin{tabular}{|c|c|c|c|}
\hline Factors & $R W(-), n=63$ & $R W(+), n=18$ & $P$ \\
\hline Fever & 6.3 & 16.7 & $\triangle_{0.180}$ \\
\hline Feeding difficulty & 19.0 & 27.8 & *0.636 \\
\hline $\mathrm{R}>60$ times $/ \mathrm{min}$ & 6.3 & 5.6 & $\triangle 1.000$ \\
\hline Chest retractions & 4.8 & 11.1 & $\triangle_{0.307}$ \\
\hline Cyanosis & 3.2 & 11.1 & $\triangle_{0.212}$ \\
\hline moderate to severe condition & 33.3 & 61.1 & 0.033 \\
\hline \multicolumn{4}{|c|}{$\begin{array}{l}\text { note: RW(+), patients with recurrent wheezing episodes; RW (-), patients without recurrent wheezing } \\
\text { episodes; R: respiratory rate. } \\
\text { Data are expressed as \% of positive cases, unless otherwise stated. }\end{array}$} \\
\hline \multicolumn{4}{|l|}{ * Continuity correction. } \\
\hline$\Delta$ Fisher exact test. & & & \\
\hline
\end{tabular}

\section{Treatment and courses between patients with and without recurrent wheezing episodes}

Systemic glucocorticoid treatment was higher in patients with recurrent wheezing episodes than in those without wheezing episodes $(P=0.031$, Continuity correction). There were no significant differences in need for oxygen treatment, length of hospital stay and the length of illness between children with and without recurrent wheezing episodes $(P>0.05)$ (Table 4).

Table 4

Comparison of treatment and courses between patients with and without recurrent wheezing episodes

\begin{tabular}{|c|c|c|c|}
\hline Factors & $R W(-), n=63$ & $\mathrm{RW}(+), \mathrm{n}=18$ & $P$ \\
\hline Oxygen inhalation & 12.7 & 16.7 & $\star 0.965$ \\
\hline Systemic glucocorticoid treatment & 36.5 & 66.7 & 0.031 \\
\hline Hospital stay $(\mathrm{d})$ & $7.63 \pm 2.07$ & $8.39 \pm 2.09$ & 0.178 \\
\hline Course of disease(d) & $14.97(10,30)$ & $16.28(11,30)$ & 0.162 \\
\hline \multicolumn{4}{|c|}{$\begin{array}{l}\text { note: RW(+), patients with recurrent wheezing episodes; RW }(-) \text {, patients without recurrent wheezing } \\
\text { episodes. } \\
\text { Data are expressed as } \% \text { of positive cases, mean } \pm \text { SD or median (minimum-maximum), unless } \\
\text { otherwise stated. }\end{array}$} \\
\hline
\end{tabular}




\section{Laboratory examinations between patients with and without recurrent wheezing episodes}

There were no significant differences between patients with and without recurrent wheezing episodes in

blood cell count, humoral immunity, cellular immunity, serum total Ig $\mathrm{E}$ and antigen-specific $\lg \mathrm{E}(P>0.05)$ (Table 5). 
Table 5

Comparison of laboratory examinations between patients with and without recurrent wheezing episodes

\begin{tabular}{llll} 
Factors & RW(-), $\mathrm{n}=63$ & $\mathrm{RW}(+), \mathrm{n}=18$ & $P$ \\
\hline Blood cell count $\left(\times 10^{9} / \mathrm{L}\right)$ & & & \\
\hline White blood cell & $9.86 \pm 3.78$ & $11.38 \pm 4.70$ & 0.159 \\
\hline Absolute lymphocyte count & $6.05 \pm 2.84$ & $7.15 \pm 2.95$ & 0.155 \\
\hline Absolute neutrophil count & $2.87(0.24-8.87)$ & $3.04(0.04-11.49)$ & 0.720 \\
\hline Eosinophil count & $0.11(0.00-0.61)$ & $0.09(0.00-0.59)$ & 0.543 \\
\hline Platelet count & $441.41 \pm 129.12$ & $454.83 \pm 109.95$ & 0.690 \\
\hline Eosinophil $(\%)$ & & & \\
\hline$<2$ & 82.5 & 83.3 & $* 1.000$ \\
\hline $2-4$ & 11.1 & 16.7 & $* 0.821$ \\
$>4$ & 6.3 & 0 & $\Delta 0.570$
\end{tabular}

Humoral immunity(g/L)

$\begin{array}{llll}\lg \mathrm{A} & 0.18(0.01-1.03) & 0.19(0.03-0.47) & 0.511 \\ \lg \mathrm{l} & 4.64(2.44-10.59) & 4.88(2.76-8.50) & 0.394 \\ \lg \mathrm{lg} & 0.65 \pm 0.33 & 0.67 \pm 0.34 & 0.804\end{array}$

Cellular immunity

$\begin{array}{llll}\mathrm{CD}^{+} & 0.63 \pm 0.10 & 0.63 \pm 0.16 & 0.918 \\ \mathrm{CD}^{+} & 0.42 \pm 0.10 & 0.43 \pm 0.11 & 0.719\end{array}$

\begin{tabular}{|c|c|c|}
\hline $\mathrm{CD}^{+}$ & $0.19 \pm 0.06$ & $0.18 \pm 0.06$ \\
\hline
\end{tabular}

$\begin{array}{lll}\mathrm{CD}^{+} / \mathrm{CD}^{+} & 2.52 \pm 1.19 & 2.67 \pm 1.26\end{array}$

$\begin{array}{llll}\text { NK } & 0.13(0.03-0.38) & 0.12(0.05-0.35) & 0.436\end{array}$
$\mathrm{CD} 19^{+} / \mathrm{CD}^{2} 3^{+}$
$0.12(0.02-0.31)$
$0.13(0.05-0.23)$
0.931

note: RW(+), patients with recurrent wheezing episodes; RW (-), patients without recurrent wheezing episodes.

Data are expressed as \% of positive cases, mean \pm SD or median (minimum-maximum), unless otherwise stated.

* Continuity correction.

$\triangle$ Fisher exact test. 


\begin{tabular}{|c|c|c|c|}
\hline Factors & $R W(-), n=63$ & $R W(+), n=18$ & $P$ \\
\hline Serum total $\lg \mathrm{E}(\mathrm{IU} / \mathrm{mL})$ & $17.13(0.20-159.50)$ & $38.71(1.90-367.00)$ & 0.345 \\
\hline \multicolumn{4}{|l|}{ Antigen-specific lg $E$} \\
\hline Milk protein & 9.1 & 20.0 & $\triangle_{0.355}$ \\
\hline Egg protein & 6.8 & 6.7 & $\triangle_{1.000}$ \\
\hline \multicolumn{4}{|c|}{$\begin{array}{l}\text { note: RW(+), patients with recurrent wheezing episodes; RW }(-) \text {, patients without recurrent wheezing } \\
\text { episodes. } \\
\text { Data are expressed as \% of positive cases, mean } \pm \text { SD or median (minimum-maximum), unless } \\
\text { otherwise stated. }\end{array}$} \\
\hline
\end{tabular}

\section{Serum level of Cytokines between patients with and without recurrent wheezing episodes}

The serum level of TNF-a was observed higher in control group compared with the patients with and without recurrent wheezing episodes $(P=0.000)$. The serum levels of IL-4,5,25,33 were observed higher in patients without recurrent wheezing episodes compared with the patients with recurrent wheezing episodes and the control (P凶0.05) (Table 6). 
Table 6

Comparison of serum level of cytokines between patients with and without recurrent wheezing episodes and control group

\begin{tabular}{|lllll|}
\hline cytokines & RW(-), $\mathbf{n}=63$ & RW(+), $\mathbf{n}=18$ & Control & $P$ \\
\hline IL-2 & $4.43(1.25-17.86)$ & $3.87(1.17-6.78)$ & $16.15(1.80-84.30)$ & 0.867 \\
\hline TNF-a * & $1.18(0.00-4.57)$ & $0.78(0.00-2.97)$ & $5.98(1.40-42.50)$ & 0.000 \\
\hline IL-4 * & $25.02(6.86-47.18)$ & $20.81(7.83-39.7)$ & $19.23(1.60-199.00)$ & 0.000 \\
\hline IL-5 * & $7.52(2.41-16.06)$ & $6.50(1.78-11.55)$ & $11.06(1.50-111.50)$ & 0.032 \\
\hline IL-13 & $3.01(0.75-6.42)$ & $2.52(1.22-4.20)$ & $8.02(1.40-85.30)$ & 0.321 \\
\hline MIP-1a & $14.25(7.68-32.24)$ & $12.98(7.61-18.85)$ & $18.35(6.10-96.50)$ & 0.275 \\
\hline IL-25 * & $60.11(19.53-124.22)$ & $48.46(15.99-108.74)$ & $31.31(1.70-434.40)$ & 0.000 \\
\hline IL-33 * & $30.84(12.69-77.18)$ & $27.93(7.75-50.12)$ & $18.56(1.30-198.40)$ & 0.000 \\
\hline TSLP & $10.34(3.98-18.42)$ & $9.01(3.27-14.16)$ & $22.96(2.20-174.50)$ & 0.569 \\
\hline MMP-9 & $\begin{array}{l}1575.09(23.71- \\
9040.32)\end{array}$ & $\begin{array}{l}1436.08(116.00- \\
6946.29)\end{array}$ & $1595.18(140.30-$ & 0.256 \\
\hline TIMP-1 & $\begin{array}{l}379.44(207.97- \\
881.72)\end{array}$ & $427.50(256.60-797.00)$ & $464.28(244.30-956.20)$ & 0.154 \\
\hline $\begin{array}{l}\text { note: RW(+), patients with recurrent wheezing episodes; RW (-), patients without recurrent wheezing } \\
\text { episodes. } \\
\text { Data are expressed as median (minimum-maximum), unless otherwise stated. } \\
\text { *Significant differences were observed between each pair of values }\end{array}$
\end{tabular}

\section{Analysis of risk factors of recurrent wheezing after bronchiolitis}

By logistic multivariable regression analysis, eczema was identified as potential risk factors for recurrent wheezing with OR $(95 \% \mathrm{Cl})$ of $7.488(1.447,38.759), \mathrm{P}<0.05$ (Table 7$)$. 
Table 7

Logistic multivariable regression of the risk factors

\begin{tabular}{|lllll|}
\hline Predictive variable & $P$ & OR & \multicolumn{2}{c|}{$95 \% \mathrm{Cl}$} \\
\cline { 4 - 5 } & & & Lower & Upper \\
\hline Eczema & 0.016 & 7.488 & 1.447 & 38.759 \\
\hline Systemic glucocorticoid treatment & 0.057 & 3.990 & 0.960 & 16.586 \\
\hline Moderate to severe condition & 0.257 & 2.381 & 0.531 & 10.674 \\
\hline TNF-a & 0.316 & 1.932 & 0.533 & 6.999 \\
\hline IL-4 & 0.521 & 0.947 & 0.801 & 1.119 \\
\hline IL-5 & 0.745 & 0.916 & 0.538 & 1.558 \\
\hline IL-25 & 0.448 & 0.968 & 0.890 & 1.053 \\
\hline IL-33 & 0.234 & 1.062 & 0.962 & 1.172 \\
\hline
\end{tabular}

\section{Discussion}

In this study, $49.4 \%$ of the infants had at least one wheezing episode, and $22.2 \%$ of the infants had experienced recurrent wheezing during the 2-year follow-up period. Several studies reported that the incidence of recurrent wheezing in infants with bronchiolitis was about $16 \% \sim 60 \%{ }^{[3-6,15-19]}$. Zhang X et al. ${ }^{[6]}$ followed up 74 Chinese infants who were hospitalized for bronchiolitis until the age of 3 years and found $35.1 \%$ of the infants had recurrent wheezing. Another 1.5 -year follow-up study ${ }^{[17]}$ showed the prevalence of post-bronchiolitis recurrent wheezing among infants was 19.4\%. In previous studies, allergy, antigen-specific Ig E, family history of asthma, exposure to smoking, severity of disease and specific pathogens or serum level of cytokines were found to be risk factors for recurrent wheezing ${ }^{[7,9-11,13]}$.

Asthmatic diseases often occur in individuals with allergic or atopic constitution, and allergic diseases may have similar pathogenesis ${ }^{[20]}$. Children with allergic constitution are more susceptible to RSV infection and have a higher risk of developing airway hyperresponsiveness ${ }^{[21]}$. In a case-control study ${ }^{[7]}$, it was found that $48 \%$ of children had recurrent wheezing, and allergic constitution was considered as a risk factor. It has been reported that allergy has the strongest correlation with eczema before 1 year old ${ }^{[22]}$. Several studies have shown that recurrent wheezing in infants is related to allergic dermatitis (eczema) $[23,24]$. Dumas o et al. ${ }^{[25]}$ analyzed the prospective data of 921 hospitalized children with bronchiolitis in 17 centers in the United States, and found that the risk of recurrent wheezing was significantly increased in children with eczema. It has been confirmed that eosinophils play a key role in the pathogenesis and development of atopic diseases including asthma and eczema ${ }^{[26,27]}$. Consistently, one study ${ }^{[28]}$ reported that recurrent wheezing at 36 months after bronchiolitis in infants was associated with eosinophilia. In our study, the proportion of infants with eczema in recurrent wheezing group was $83.3 \%$, which was 
significantly higher than that of non-recurrent wheezing group. Multivariate regression analysis suggested that eczema was the only independent risk factor for recurrent wheezing post bronchiolitis. Therefore, it is suggested that early intervention should be carried out in infants with bronchiolitis accompanied by eczema in order to reduce the incidence of recurrent wheezing.

Several prior studies have reported that RSV infection in early life may have profound impact for the development of recurrent wheezing and/or asthma ${ }^{[5,13,29]}$. Other studies demonstrating that hRV-related bronchiolitis may be associated with an increased prevalence of recurrent wheezing and asthma in later childhood $^{[9,30]}$. However, studies by teeratakulpisan $\mathrm{J}$ et al. ${ }^{[16]}$ and Valkonen $\mathrm{H}$ et al. ${ }^{[31]}$ had found no consistent relationship between the type of virus infected and recurrent wheezing. In our study, $44.4 \%$ of the infants were infected with RSV and 3.7\% were infected with hRV. We found there was no significant difference in virus infected with recurrent wheezing after bronchiolitis. It is suggested that whether the virus infected in infants with bronchiolitis can be used as a predictor of recurrent wheezing need further study.

Two demographically and clinically important differences we observed in our study between the two groups, namely, the percentage of infants with moderate to severe bronchiolitis and the usage of systemic glucocorticoid were significantly higher in infants with recurrent wheezing. A longitudinal study ${ }^{[11]}$ found that in 343 children with bronchiolitis caused by RSV, the severity of the disease can be used as a predictor of asthma and atopic diseases. One 7-year follow-up study ${ }^{[32]}$ showed prednisolone could reduce recurrent wheezing after first rhinovirus infection while another study ${ }^{[3]}$ showed dexamethasone could not reduce recurrent wheezing post bronchiolitis 1 year later. In our study, we didn't find that severe bronchiolitis was a risk factor for recurrent wheezing.

The pathogenesis of bronchiolitis is mainly related to excessive type 2 and/or deficient type 1 immune responses ${ }^{[34]}$.Plasma level of TNF-a, which originates from Th1 cytokine, has been reported to be of great significance in predicting the development of recurrent wheezing during acute bronchiolitis ${ }^{[35]}$. The serum level of IL-3IIL-4IIL-10IIL-13, which originates from Th2 cytokine, were higher in children with RSV bronchiolitis secondary wheezing, and IL-3 can be used as a predictor of recurrent wheezing ${ }^{[14]}$. In our study, the levels of TNF-a, IL-4, IL-5, IL-25 and IL-33 were significant different from the patients with and without recurrent wheezing episodes and the control group. This furtherly confirmed that bronchiolitis was related to T helper cell 1 (Th1)/T helper cell 2 (Th2) imbalance. However, multivariate regression analysis showed that there was no significant difference in serum cytokine levels between two groups. This may be related to the fact that we are testing serum samples rather than nasopharynx aspirate.

In conclusion, the prevalence of recurrent wheezing among infants after bronchiolitis was $22.2 \%$ in 2 years of follow-up. The risk factor for recurrent wheezing after acute bronchiolitis is eczema. No correlation was found between the pathogens and severity of disease with recurrent wheezing post bronchiolitis. 
Our study has limitations. First of all, our study sample size was small and the follow-up time was relatively short. Secondly, we could not confirm whether parents gave reliable information in the phone interview. Thirdly, no pathogen detection was performed for every wheezing attack post bronchiolitis.

\section{Declarations}

\section{Conflicts of interest}

The authors declare that they have no conflict of interest.

\section{References}

1. Robledo-Aceves M, Moreno-Peregrina MJ, Velarde-Rivera F, Ascencio-Esparza E. Risk factors for severe bronchiolitis caused by respiratory virus infections among Mexican children in an emergency department.Medicine 2018;97(9):e0057.https://doi.org/1097/MD.0000000000010057.

2. Cui DW, Feng LZ, Chen Y, Lai SJ, Zhang ZK, Yu F, et al. Clinical and Epidemiologic Characteristics of Hospitalized Patients with Laboratory-Confirmed Respiratory Syncytial Virus Infection in Eastern China between 2009 and 2013: A Retrospective Study. PloS one 2016; 11(11). https://doi.org/ 10.1371/journal.pone.0165437.

3. Rinawi F, Kassis I, Tamir R, Kugelman A, Srugo I, Miron D. Bronchiolitis in young infants: is it a risk factor for recurrent wheezing in childhood? World journal of pediatrics: WJP 2017; 13(1):41-8. https://doi.org/ 10.1007/s12519-016-0056-4.

4. Mansbach JM, Luna PN, Shaw CA, Hasegawa K, Petrosino JF, Piedra PA, et al. Increased Moraxella and Streptococcus species abundance after severe bronchiolitis is associated with recurrent wheezing. J Allergy Clin Immunol 2020; 145(2):518-27 e518. https://doi.org/ 10.1016/j.jaci.2019.10.034.

5. Bacharier LB, Cohen R, Schweiger T, Yin-Declue H, Christie C, Zheng J, et al. Determinants of asthma after severe respiratory syncytial virus bronchiolitis. J Allergy Clin Immunol 2012; 130(1):91-100 e103. https://doi.org/ 10.1016/j.jaci.2012.02.010.

6. Zhang X, Zhang X, Zhang N, Wang X, Sun L, Chen N, et al. Airway microbiome, host immune response and recurrent wheezing in infants with severe respiratory syncytial virus bronchiolitis. Pediatric allergy immunology: official publication of the European Society of Pediatric Allergy Immunology 2019. https://doi.org/ 10.1111/pai.13183.

7. de Sousa RB, Medeiros D, Sarinho E, Rizzo JA, Silva AR, Bianca AC. Risk factors for recurrent wheezing in infants: a case-control study. Revista de saude publica 2016; 50:15. https://doi.org/.

8. Sarria EE, Rita M, Weiguo Y, Valentina C, Tiller CJ, Jeffrey K, et al. Atopy, cytokine production, and airway reactivity as predictors of pre-school asthma and airway responsiveness. 2014; 49(2):132139. https://doi.org/ 10.1002/ppul.22784. 
9. Midulla F, Pierangeli A, Cangiano G, Bonci E, Salvadei S, Scagnolari C, et al. Rhinovirus bronchiolitis and recurrent wheezing: 1-year follow-up. The European respiratory journal 2012; 39(2):396-402. https://doi.org/ DOI: 10.1183/09031936.00188210.

10. Nicolai A, Frassanito A, Nenna R, Cangiano G, Petrarca L, Papoff P, et al. Risk Factors for Virusinduced Acute Respiratory Tract Infections in Children Younger Than 3 Years and Recurrent Wheezing at 36 Months Follow-Up After Discharge. Pediatr Infect Dis J 2017; 36(2):179-83. https://doi.org/ 10.1097/INF.0000000000001385.

11. Lu S, Hartert TV, Everard ML, Giezek H, Nelsen L, Mehta A, et al. Predictors of asthma following severe respiratory syncytial virus (RSV) bronchiolitis in early childhood. 2016; 51(12):1382-1392. https://doi.org/ 10.1002/ppul.23461.

12. Fauroux B, Simoes EAF, Checchia PA, Paes B, Figueras-Aloy J, Manzoni P, et al. The Burden and Longterm Respiratory Morbidity Associated with Respiratory Syncytial Virus Infection in Early Childhood. Infect Dis Ther 2017; 6(2):173-97. https://doi.org/ 10.1007/s40121-017-0151-4.

13. Escobar GJ, Masaquel AS, Li SX, Walsh EM, Kipnis P. Persistent recurring wheezing in the fifth year of life after laboratory-confirmed, medically attended respiratory syncytial virus infection in infancy. BMC Pediatr 2013; 13:97. https://doi.org/ 10.1186/1471-2431-13-97.

14. Bertrand P, Lay MK, Piedimonte G, Brockmann PE, Palavecino CE, Hernandez J, et al. Elevated IL-3 and IL-12p40 levels in the lower airway of infants with RSV-induced bronchiolitis correlate with recurrent wheezing.Cytokine 2015;76(2):417-423.https://doi.org/10.1016/j.cyto.2015.07.017.

15. Sugai K, Kimura H, Miyaji Y, Tsukagoshi H, Yoshizumi M, Sasaki-Sakamoto T, et al. MIP-1alpha level in nasopharyngeal aspirates at the first wheezing episode predicts recurrent wheezing. J Allergy Clin Immunol 2016; 137(3):774-81. https://doi.org/ 10.1016/j.jaci.2015.08.032.

16. Teeratakulpisarn J, Pientong C, Ekalaksananan T, Ruangsiripiyakul H, Uppala R. Rhinovirus infection in children hospitalized with acute bronchiolitis and its impact on subsequent wheezing or asthma: a comparison of etiologies. Asian Pacific journal of allergy immunology 2014; 32(3):226-34. https://doi.org/ 10.12932/AP0417.32.3.2014.

17. $10.1038 /$ srep31165

Nuolivirta K, Törmänen S, Teräsjärvi J, Vuononvirta J, Koponen P, Korppi M, et al. Post-bronchiolitis wheezing is associated with toll-like receptor 9 rs187084 gene polymorphism. 2016; 6:31165. https://doi.org/ 10.1038/srep31165.

- Korppi M, Nuolivirta K, Lauhkonen E, Holster A, Terasjarvi J, Vuononvirta J, et al. IL-10 gene polymorphism is associated with preschool atopy and early-life recurrent wheezing after bronchiolitis in infancy. Pediatric pulmonology 2017; 52(1):14-20. https://doi.org/ 10.1002/ppul.23489.

- Szulman GA, Freilij H, Behrends I, Gentile A, Mallol J. [Recurrent wheezing: prevalence and associated factors in infants from Buenos Aires City, Argentina]. Boletin medico del Hospital Infantil de Mexico 2017; 74(6):419-426. https://doi.org/ 10.1016/j.bmhimx.2017.08.001.

- Hon KL, Tsang KYC, Pong NHH, Leung TF. Relevance of Cat and Dog Sensitization by Skin Prick Testing in Childhood Eczema and Asthma. Curr Pediatr Rev 2017; 13(2):120-5. https://doi.org/ 
- Relic T, llic N, Kostic G, Jovanovic D, Tambur Z, Lazarevic I. Respiratory syncytial virus infection and bronchial hyperreactivity in children up to two years of age in correlation with atopy. Vojnosanitetski pregled 2016; 73(1):59-65. https://doi.org/ 10.2298/vsp140930030r.

- Ballardini N, Bergstrom A, Wahlgren CF, van Hage M, Hallner E, Kull I, et al. IgE antibodies in relation to prevalence and multimorbidity of eczema, asthma, and rhinitis from birth to adolescence. Allergy 2016; 71(3):342-9. https://doi.org/ 10.1111/all.12798.

- Pellegrini-Belinchon J, Lorente-Toledano F, Galindo-Villardon P, Gonzalez-Carvajal I, Martin-Martin J, Mallol $\mathrm{J}$, et al. Factors associated to recurrent wheezing in infants under one year of age in the province of Salamanca, Spain: Is intervention possible? A predictive model. Allergologia et immunopathologia 2016; 44(5):393-399. https://doi.org/10.1016/j.aller.2015.09.001.

- Shen R, Meng-Rong LI, Zhang LT, Zheng BJCJoCHC. Analysis of the correlation between the asthma predictive index and bronchiolitis at the first in infants and the forthcoming repeated wheezing. 2017. https://doi.org/.

- Dumas O, Hasegawa K, Mansbach JM, Sullivan AF, Piedra PA, Camargo CA, Jr. Severe bronchiolitis profiles and risk of recurrent wheeze by age 3 years. The Journal of allergy and clinical immunology 2018. https://doi.org/ 10.1016/j.jaci.2018.08.043.

- McBrien CN, Menzies-Gow A. The Biology of Eosinophils and Their Role in Asthma. Front MedLausanne 2017; 4. https://doi.org/ 10.3389/fmed.2017.00093.

- Rossberg S, Gerhold K, Geske T, Zimmermann K, Menke G, Zaino M, et al. Elevated blood eosinophils in early infancy are predictive of atopic dermatitis in children with risk for atopy. Pediatric allergy immunology: official publication of the European Society of Pediatric Allergy Immunology 2016; 27(7):702-8. https://doi.org/ 10.1111/pai.12607.

- Midulla F, Nicolai A, Ferrara M, Gentile F, Pierangeli A, Bonci E, et al. Recurrent wheezing 36 months after bronchiolitis is associated with rhinovirus infections and blood eosinophilia. Acta paediatrica 2014; 103(10):1094-9. https://doi.org/ 10.1111/apa.12720.

- Régnier SA, Jasper HJPIDJ. Association between respiratory syncytial virus hospitalizations in infants and respiratory sequelae: systematic review and meta-analysis. 2013; 32(8):820-826. https://doi.org/ 10.1097/INF.0b013e31829061e8.

- Aya T, Koichi H, Masatoki S, Toshiko S, Yoichi T, Ryo M, et al. Clinical and epidemiologic factors related to subsequent wheezing after virus-induced lower respiratory tract infections in hospitalized pediatric patients younger than 3 years. 2014; 173(7):959-966. https://doi.org/ 10.1007/s00431-014-2277-7.

- Valkonen H, Waris M, Ruohola A, Ruuskanen O, Heikkinen T. Recurrent wheezing after respiratory syncytial virus or non-respiratory syncytial virus bronchiolitis in infancy: a 3-year follow-up. Allergy 2009; 64(9):1359-65. https://doi.org/ 10.1111/j.1398-9995.2009.02022.x.

- Lukkarinen M, Lukkarinen H, Lehtinen P, Vuorinen T, Ruuskanen O, Jartti T. Prednisolone reduces recurrent wheezing after first rhinovirus wheeze: a 7-year follow-up. Pediatric allergy and immunology: 
official publication of the European Society of Pediatric Allergy and Immunology 2013; 24(3):237-243. https://doi.org/ 10.1111/j.1398-9995.2009.02022.x.

- Tagarro A, Perez L, Quintero VM, Canete A. Dexamethasone does not reduce length of hospitalization or recurrent wheezing 1 year after early bronchiolitis. Minerva pediatrica 2014; 66(2):131-40. https://doi.org/ 10.1017/S1047951113000498.

- Legg JP, Hussain IR, Warner JA, Johnston SL, Warner JOJAJRCCM. Type 1 and type 2 cytokine imbalance in acute respiratory syncytial virus bronchiolitis. 2003; 168(6):633-639. https://doi.org/ 10.1164/rccm.200210-1148oc.

- Chkhaidze I, Zirakishvili D, Shavshvishvili N, Barnabishvili NJPIAP. Prognostic value of TH1/TH2 cytokines in infants with wheezing in a three year follow-up study. 2016; 84(3):144. https://doi.org/ 10.5603/PiAP.2016.0016.

\section{Figures}

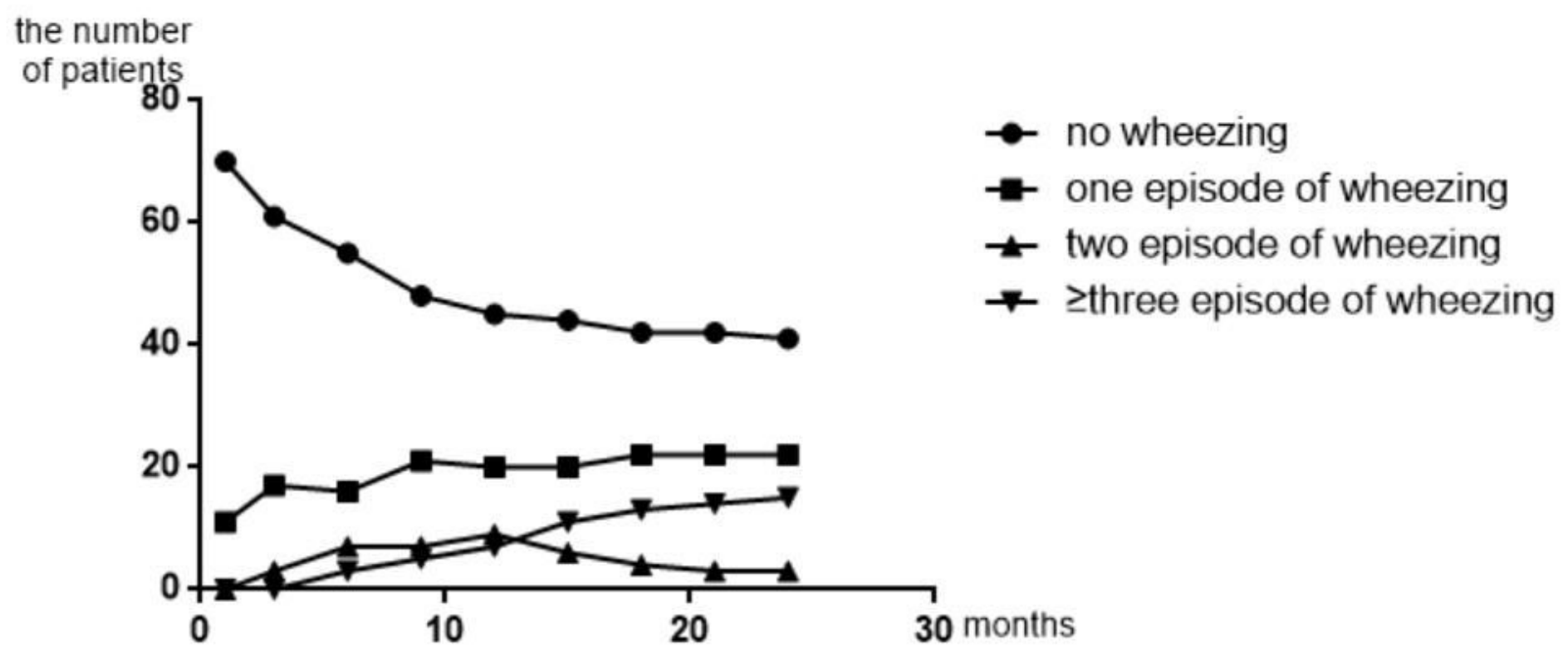

\section{Figure 1}

Tendency of wheezing episodes with time in infants with bronchiolitis 